\title{
Severe form of thyroid hormone resistance in a patient with homozygous/hemizygous mutation of $\mathrm{T} 3$ receptor gene
}

\author{
Karin Frank-Raue, Angela Lorenz, Christine Haag, Wolfgang Höppner ${ }^{1}$, Hans-Ullrich Boll ${ }^{2}$, Dietrich Knorr ${ }^{3}$, \\ Sabine Hentze and Friedhelm Raue \\ Endokrinologisch-humangenetische Gemeinschaftspraxis, Brückenstr. 21, 69120 Heidelberg, ${ }^{1}$ Institut für Hormon und Fertilitätsforschung, Grandweg \\ 64, 22529 Hamburg, ${ }^{2}$ Johannes Anstalten, Neckarburkeneshr. 2-4, 74821 Mosbach and ${ }^{3}$ Ludwig Maximilians Universität, Kinderspital, Lindwurmstr. \\ 4, 80337 München, Germany \\ (Correspondence should be addressed to K Frank-Raue; Email: raue-heidelberg@t-online.de)
}

\begin{abstract}
Resistance to thyroid hormone syndrome (RTH) is a rare disorder, usually inherited as an autosomal dominant trait. Patients with RTH are usually euthyroid but can occasionally present with signs and symptoms of thyrotoxicosis or rarely with hypothyroidism. Affected individuals are usually heterozygous for mutations in the thyroid hormone receptor $\beta$ gene (TR- $\beta$ ).

We present a patient with RTH found to be homo-/hemizygous for a mutation in the TR- $\beta$ gene. The single nucleotide substitution I280S $(1123 \mathrm{~T} \rightarrow \mathrm{G})$ was present either on both alleles or in a hemizygous form with complete deletion of the second allele. The I280S mutation was recently reported in a heterozygous patient. The severe phenotype with seriously impaired intellectual development, hyperkinetic behaviour, tachycardia, hearing and visual impairment is probably due to the dominant negative effect of the I280S mutant protein and the absence of any functional TR- $\beta$.
\end{abstract}

European Journal of Endocrinology 150 819-823

\section{Introduction}

Resistance to thyroid hormone syndrome (RTH) is a rare disorder, usually inherited as an autosomal dominant trait. Patients with RTH are usually euthyroid but can occasionally present with signs and symptoms of thyrotoxicosis or rarely with hypothyroidism. The syndrome is characterized biochemically by elevated serum thyroid hormone levels, non-suppressed thyroid-stimulating hormone (TSH) and reduced tissue responsiveness to thyroid hormones. Affected individuals are usually heterozygous for mutations in the thyroid hormone receptor $\beta$ gene (TR- $\beta$ ). Most mutations are located in three hot spots encoding the tri-iodothyronine (T3)-binding domain of the receptor. Consequently, the ability of the mutant proteins to bind T3 is moderately or markedly reduced and their ability to activate or repress target gene expression is impaired. The mutant receptors are also able to inhibit their wild-type counterparts in a dominant negative manner $(1,2)$. This dominant negative effect (DNE) of mutant TRs can be explained in different ways. Available data support the notion that the DNE is mediated by mutant transcriptionally inactive TR complexes that bind to thyroid hormone response elements located in the promoters of target genes (3). Some rare RTH families without mutations of the TR- $\beta$ gene have been described (4).

Interestingly, the patient in whom RTH was first described $(5,6)$, was found to be homozygous for a complete deletion of both alleles of the TR- $\beta$ receptor gene. The obligate heterozygotes in this family, harbouring a deletion of one TR- $\beta$ allele, were completely normal with no evidence of thyroid dysfunction. Therefore, mere deletion of one copy of TR- $\beta$ receptor fails to result in the typical RTH phenotype because the DNE is absent.

It has been described that truncated TR- $\beta$ can cause severe phenotypes. The affected individuals were heterozygous for a point mutation in the TR- $\beta$ gene, which gave rise to a premature stop codon and a TR- $\beta$ with a truncated ligand binding domain. TR- $\beta$ lacking the last 20 (7) or 28 (8) amino acids induces severe RTH phenotypes including mental retardation, severe visual and auditory deficits and short stature.

On the other hand, there is a single case in which severe resistance was associated with marked developmental delay and growth retardation (9). This individual was homozygous for a mutation in both alleles of the TR- $\beta$ gene, and the extreme phenotype presumably reflects the inhibitory effects of two dominant negative mutated alleles. This child had a resting heart rate of 
190 beats/min and died from cardiogenic shock complicating staphylococcal pneumonia at the age of 7 years (10).

We now report a 27-year-old patient with a severe form of RTH resulting from homozygosity or hemizygosity for a point mutation in the TR- $\beta$ gene (I280V). This mutation has previously been described in a heterozygous typical RTH variant (11).

\section{Case report}

The female patient was born in 1977 as the second child of a 20-year-old mother known to have a goitre. The birth weight was $3000 \mathrm{~g}$. Postnatal illness included respiratory distress. No goitre was initially observed in the patient. Normal values for thyroid hormones and TSH were documented at birth. Within the first days of life increasing thyroid size, muscle weakness, sweating and tachycardia (185 beats/min) were recognized; 2 weeks later elevated thyroid hormone levels and TSH were measured. The patient was hospitalized during the first 7 months of her life due to breathing problems associated with upper respiratory tract infections.

At the age of 3 months levothyroxine therapy was initiated because of massive TSH elevation. After some weeks the TSH dropped but T3 and thyroxine (T4) remained elevated. Because of sweating, tachycardia and persistently elevated thyroid hormone levels, hyperthyroidism was suspected and anti-thyroid drug medication (methimazole, $2.5 \mathrm{mg}$ ) was started at the age of 5 months and continued until the age of 14 months at a steady dosage. Under this treatment total $\mathrm{T} 4$ was $248 \mathrm{nmol} / \mathrm{l}$, total T3 was $10.4 \mathrm{nmol} / \mathrm{l}$, TSH $70 \mathrm{mU} / \mathrm{l}$; after TRH injection TSH increased to $300 \mathrm{mU} / \mathrm{l}$. Because of goitre along with elevated thyroid hormone and TSH levels, RTH was suspected at the University of Munich. After withdrawal of anti-thyroid drugs, T4 increased to $358 \mathrm{nmol} / \mathrm{l}$ and TSH went down but was still elevated; thyroid enlargement decreased.

At the age of 1 year and 8 months the patient had a height of $81 \mathrm{~cm}$, a weight of $9500 \mathrm{~g}$, tachycardia (140 beats/min) and evidence of developmental delay, being unable to stand without help. Goitre was documented.

At the age of 3 years, severe psychomotor developmental delay was obvious, the patient was not able to walk; hearing loss and visual impairment (myopia 9 dioptries) were found. At the age of 3 years and 10 months ear, nose and throat (ENT) investigations were initiated. Enlarged pharyngeal tonsils and chronic otitis media were diagnosed. Brainstem evoked response audiometry (BERA) showed a mixed sensorineural and conductive hearing defect $(30 \mathrm{~dB}$ right ear, $40 \mathrm{~dB}$ left ear at $3000 \mathrm{~Hz}$ ) which remained unchanged after adenoidectomy and paracentesis of the right eardrum. A central hearing defect was therefore diagnosed.
Until the age of 3 years, height and weight were on the 3rd percentile, at the age of 7 on the 10th and after the age of 10, they were continuously on the 25th percentile.

At the age of 9 years, thyroid surgery was carried out because of massive goitre with respiratory problems. Without medication TSH was $33 \mathrm{mU} / \mathrm{l}$ preoperatively. After the initial thyroid surgery TSH levels increased to $203 \mathrm{mU} / \mathrm{l}$ and $\mathrm{T} 4$ at $25 \mu \mathrm{g} /$ day was initiated. Most of the documented TSH levels thereafter were above the level of $33 \mathrm{mU} / \mathrm{l}$ (between 49 and $94 \mathrm{mU} / \mathrm{l}$ ) suggesting insufficient dosage of L-T4, e.g. at the age of 11 years $125 \mu \mathrm{g} \mathrm{L-T4}$ per day was given. The patient developed recurrent goitre and at the ages of 13 and 16 years was treated surgically for the second and third time respectively.

We saw the patient first when she was 20 years old. Height was $164 \mathrm{~cm}$, weight $51 \mathrm{~kg}$, blood pressure 120/90 mmHg. Tachycardia was present with 132 beats/min; diffuse sweating, hyperactivity and hyperkinetic behaviour was found.

Intellectual development was severely impaired: the patient lived in a nursing home, no active speech was possible, simple tasks and basic functions could be carried out independently. When requested to draw a person she drew a head with legs. The stage of her intellectual development was established at that of a 4 year old with her IQ being below 60. Electroencephalogram (EEG) was normal. Thyroid ultrasound showed thyroid remnants with a volume of $9 \mathrm{ml}$, low echogenicity of the whole thyroid gland and no thyroid nodules.

Free T4, free T3, TSH and TSH after TRH were elevated (Table 1). Osteocalcin and angiotensin-converting enzyme were slightly elevated. Magnetic resonance imaging of the brain was not performed.

Within the next 5 years, thyroid remnant increased from 9 to $18 \mathrm{ml}$ and two nodules ( 6 and $4 \mathrm{ml}$ ) developed showing increased uptake on scintiscan. On her last visit at the age of 25 years, TSH level was $19 \mathrm{mU} / \mathrm{l}$ and because of the enlargement of thyroid residue, L-T4 was increased to $150 \mu \mathrm{g} /$ day and atenolol was added.

The mother of our patient had a thyroidectomy because of goitre with tracheal stenosis at the age of 25 years. Her height is $169 \mathrm{~cm}$ and weight $80 \mathrm{~kg}$. Her free T4, free T3 and TSH values were within the normal range (Table 1), while taking $100 \mu \mathrm{g}$ L-T4 per day. Ultrasound showed a slight enlargement of thyroid remnant on the left side $(13 \mathrm{ml})$. The only manifestation of RTH is a goitre without any other symptoms or pathological laboratory values. She seems to have normal peripheral sensitivity to thyroid hormones because osteocalcin, bone alkaline phosphatase, sex hormone-binding globulin (SHBG) and angiotensinconverting enzyme are within the normal range.

She reported that her son, born 1 year before our index case from a different father, has no medical problems, in particular no thyroid disease. His thyroid hormone levels 
Table 1 Laboratory findings.

\begin{tabular}{|c|c|c|c|c|}
\hline \multirow[b]{2}{*}{ Parameter (reference range) } & \multicolumn{3}{|c|}{ Patient } & \multirow[b]{2}{*}{ Mother of patient (45 years) } \\
\hline & 10 years & 20 years & 25 years & \\
\hline FT4 (10-21 pmol/l) & & 41 & 45 & 18 \\
\hline FT3 $(3.1-6.9 \mathrm{pmol} / \mathrm{l})$ & & 9.4 & 8.6 & 4.9 \\
\hline TSH $(0.35-4.5 \mathrm{mU} / \mathrm{l})$ & & 24 & 19 & 1.5 \\
\hline TSH after TRH & & 146 & & \\
\hline Osteocalcin $(4-12 \mathrm{ng} / \mathrm{ml})$ & & 14 & 9 & 9 \\
\hline Bone alkaline phosphatase $(4-20 \mathrm{ng} / \mathrm{ml})$ & & & 16 & 13 \\
\hline SHBG $(18-114 \mathrm{nmol} / \mathrm{l})$ & 66 & & $>180$ & 52.7 \\
\hline Angiotensin-converting enzyme (60 U/l) & & 69 & 63 & 60 \\
\hline Medical therapy & $? \mathrm{~L}-\mathrm{T}_{4}$ & $100 \mu \mathrm{g} \mathrm{L}-\mathrm{T}_{4}$ & $125 \mu \mathrm{g} \mathrm{L-T}$ oral contraceptive & $100 \mu \mathrm{g} \mathrm{L-T}$ \\
\hline
\end{tabular}

FT4 and FT3, free T4 and free T3 respectively; SHBG, sex hormone-binding globulin.

and TSH level are in the normal range. There is no consanguinity between the parents of our patient. The father of our patient declines the offer of investigation.

Genetic analysis of the index case and her mother was performed by standard procedures as follows. Genomic DNA was prepared from blood leukocytes and exons $7-10$ of the TR- $\beta$ gene were amplified by PCR). PCR-amplified DNA was sequenced by cycle sequencing using the fluorescence-labelled dideoxy terminators and visualized on an automated sequencer (Applied Biosystems,Weiterstadt, Germany).

Genetic analysis found an apparently homozygous single nucleotide substitution $1123 \mathrm{~T} \rightarrow \mathrm{G}$ resulting in I280S in the patient (Fig. 1). However, a deletion of the entire coding region of one TR- $\beta$ allele could not be excluded since all investigated polymorphisms in the exons 7-10 and intron 4 (cytosine adenosine (CA)-repeat) were homozygous. The patient's mother was heterozygous for I280S.

The genotype in the father of our patient could not be determined since he declines all investigation.

\section{Discussion}

We present a patient with RTH found to be homozygous or, alternatively, hemizygous for missense mutation in the TR- $\beta$ gene. The severe phenotype with seriously impaired intellectual development, hyperkinetic behaviour, tachycardia, hearing loss and visual impairment is probably due to the dominant negative effect of the mutant TR- $\beta$ protein and complete absence of any functional TR- $\beta$.

The majority of RTH cases that have been described are dominantly inherited with highly variable clinical features (12). In nearly all cases only one copy of TR- $\beta$ is mutated and one wild-type allele is demonstrable. Many patients with RTH are either asymptomatic or have non-specific symptoms and are noted to have a goitre like the mother of our patient. Characteristic thyroid function tests are elevated free $\mathrm{T} 4$ and free T3 concentrations with non-suppressed TSH. The high thyroid hormone levels are thought to compensate for ubiquitous tissue resistance, producing a euthyroid state. A number of RTH individuals with the same biochemical abnormalities exhibit signs and symptoms associated with thyrotoxicosis. Margotat and collaborators (11) reported a French family with RTH caused by heterozygosity for the $\mathrm{I} 280 \mathrm{~V}$ mutation. In this family the index case presented with symptoms of hyperthyroidism, goitre and elevated TSH (19 mU/l). The phenotype of the other family members of this family was not described. The mother of our patient
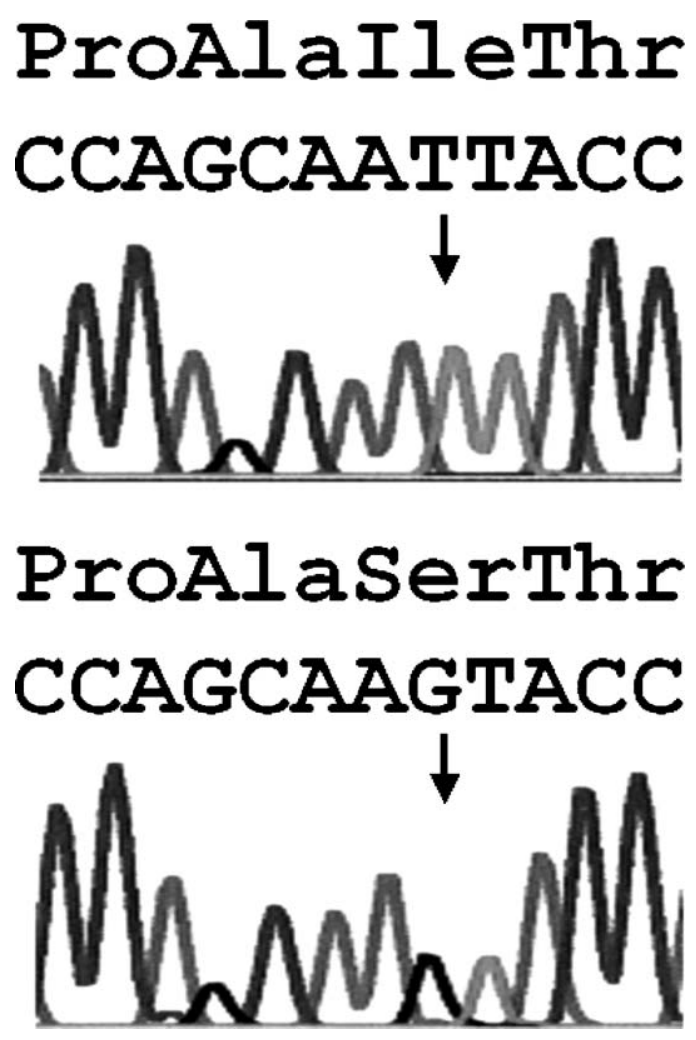

Figure 1 The mutation of the thyroid hormone receptor $\beta$ gene in the index case. Upper panel showing the unaffected control (arrow). Lower panel showing a single nucleotide substitution $\mathrm{T} \rightarrow \mathrm{G}$ (position 1123) resulting in lle 280 Ser (arrow) either in a homozygous or a hemizygous variant. 
with the same mutation shows no signs of hyperthyroidism and has normal thyroid hormone levels and normal TSH while taking $100 \mu \mathrm{g}$ L-T4 per day, her only symptom of RTH being goitre. This confirms the known variability of phenotype in patients with the same mutation.

Positive correlations between free $\mathrm{T} 3$ and heart rate have been shown in RTH (13). Neurophysiological abnormalities such as attention deficit hyperactivity disorder in childhood or language development problems manifested by poor reading skills, dyslexia and problems with articulation have been documented in a large number of patients with RTH $(1,2,14)$.

The phenotype of RTH in our patient is overtly different from that of individuals with RTH due to heterozygous mutations in the TR- $\beta$ gene. The initial presentation with early development of goitre, hyperactivity and severe tachycardia as well as severely impaired intellectual development and the magnitude of biochemical abnormalities are much more pronounced than is usual in cases of heterozygous RTH. One may argue that to some degree, the severity of the phenotype may be heightened by treatment in childhood, in particular that the anti-thyroid drug treatment over a 10-month period in the first 2 years of life may have worsened intellectual development. Also the degree of TSH elevation in the years after thyroidectomy at the age of 9 years may have had an influence on the development of recurrent goitre. With regard to growth and weight, there seems to have been some catch-up during childhood from the 3rd to the 25 th percentile by the age of 10 years.

Severe mental retardation is quite uncommon in $\mathrm{RTH}$, in one series fewer than $5 \%$ of patients had IQs below 70 (14). Sinus tachycardia is very common in RTH patients, some studies reporting frequency as high as $80 \%$ (12). One recent study (13) showed mild tachycardia in RTH patients with an average resting heart rate of 83 beats/min (range 57-107), whereas in our patient the pulse rate was clearly elevated.

Severe thyroid hormone resistance also can be induced by truncated TR- $\beta$ mutants $(7,8)$. In one study (15) three deletion mutant TR- $\beta$ s from patients with RTH that led to receptors lacking 11, 13 and 16 amino acids had negligible T3 binding and transcriptional activation and strong dominant negative activity over the wild-type receptor. Two of the three patients had very severe phenotypes including impaired speech development, impaired hearing and mental retardation. The third patient, however, had a very mild phenotype.

The most severe resistance described to date with a homozygous mutation at codon 337 of the TR- $\beta$ gene was seen in the Bercu patient (9). There was markedly delayed growth and skeletal maturation, developmental delay, mental retardation and hyperactivity. This patient's T3 and T4 levels were extremely elevated in the same order of magnitude as those found in a patient with a heterozygous mutation leading to a truncated TR- $\beta$ lacking 20 amino acids (7). In the Bercu patient, TSH levels were also dramatically elevated in contrast to one patient with truncated TR- $\beta$ (7).

Our patient is not as severely affected either clinically or biochemically as the Bercu patient. The maximum reported TSH levels were 387 vs $24 \mathrm{mU} / \mathrm{l}$ respectively (Table 2). Serum free T4 in our patient was twice the upper limit of normal as compared with the Bercu patient who had T4 levels that were elevated four-fold.

Central to the pathogenesis of RTH is the interference of mutant TR- $\beta s$ with the function of the wild-type TRs, a phenomenon that explains the dominant mode of RTH inheritance. A detailed explanation of how a given mutation gives rise to a particular phenotype is still lacking. Obviously, as demonstrated in our patient, the dominant negative effect of mutant protein in conjunction with the absence of any intact TR- $\beta$ leads to a much more severe clinical and biochemical phenotype of RTH. Whether or not a dosage difference caused by homozygosity or hemizygosity for a particular mutation may be associated with difference in the clinical phenotype is unknown. However, any such effect would be expected to be small. Both genotypes lack intact TR$\beta$. It may be that homozygosity is usually lethal as so few patients with this genotype have been described, but in some instances survival into adult life seems to be possible. Not only the lethality, but perhaps even more the rarity of RTH may be an explanation for the very low incidence of homozygous patients.

Table 2 Published RTH with homozygous mutation in the TR- $\beta$ gene.

\begin{tabular}{|c|c|c|c|}
\hline & \multicolumn{3}{|c|}{ Reference } \\
\hline & Refetoff $(1991)(5,6)$ & Bercu (1991) (9) & Frank-Raue (2004) \\
\hline Genetics & $\begin{array}{l}\text { Complete deletion of } \\
\text { both TR } \beta \text { alleles }\end{array}$ & $\begin{array}{l}\text { Single nucleotide } \\
\text { substitution: Thr } 337\end{array}$ & Single nucleotide substitution: Ser 280 \\
\hline Signs and symptoms & $\begin{array}{l}\text { Normal height and } \\
\text { intelligence, hearing loss }\end{array}$ & $\begin{array}{l}\text { Growth and severe } \\
\text { mental retardation }\end{array}$ & $\begin{array}{l}\text { Hypermetabolism, severe mental retardation, } \\
\text { hearing loss }\end{array}$ \\
\hline Laboratory findings & $\begin{array}{l}\text { TSH, } 5.8 \mathrm{mU} / \mathrm{l} ; \\
\text { TT4, } 309 \mathrm{nmol} / \mathrm{l}(50-160)\end{array}$ & $\begin{array}{l}\text { TSH } 387 \mathrm{mU} / \mathrm{l} \\
\text { TT4 } 643 \mathrm{nmol} / \mathrm{l}(50-160)\end{array}$ & TSH, 24 mU/l; FT4 41pmol/l (10-21) \\
\hline Heterozygous parents & Normal phenotype & Euthyroid goiter & Mother euthyroid goiter \\
\hline
\end{tabular}


The diagnosis of RTH confirmed by genetic studies in the affected child and the mother should prevent further surgical interventions, the likelihood of recrudescence of the goitre being high (2).

Three different pathophysiological mechanisms which induce severe forms of RTH have been characterised to date: (1) heterozygous point mutations that cause a truncated TR- $\beta$ (several cases in the literature); (2) autosomal recessive inheritance of a deletion of both copies of TR- $\beta$ (one case in the literature); (3) homo/hemizygous point mutations (to which we have now added another case in the literature).

\section{References}

1 Refetoff S, Weiss RE \& Usala SJ. The syndromes of resistance to thyroid hormone. Endocrine Reviews 199314 348-399.

2 Chatterjee VKK \& Beck-Peccoz P. Thyroid homone resistance. Bailliere's Clinical Endocrinology and Metabolism 19948 267-283.

3 Yen PM. Molecular basis of resistance to thyroid hormone. Trends in Endocrinology and Metabolism 200314 327-333.

4 Pohlenz J, Weiss RE, Macchia PE, Pannain S, Lau IT, Ho H et al. Five new families with resistance to thyroid hormone not caused by mutations in the thyroid hormone receptor gene. Journal of Clinical Endocrinology and Metabolism 199984 3919-3928.

5 Refetoff S, DeWind LT \& DeGroot LJ. Familial syndrome combining deaf-mutism, stippled epiphysis, goitre, and abnormal high PBI: possible target organ refractoriness to thyroid hormone. Journal of Clinical Endocrinology and Metabolism 196727 279-294.

6 Usala SJ, Menke JB, Watson TL, Wondisford FE, Weintraub BD, Berard $\mathrm{J}$ et al. A homozygous deletion in the c-erbA $\beta$ thyroid hormone receptor gene in a patient with generalized thyroid hormone resistance: isolation and characterization of the mutant receptor. Molecular Endocrinology $19915327-335$.

7 Phillips SA, Rotmann-Pikienlny P, Lazar J, Ando S, Hauser P, Skarulis MC et al. Extreme thyroid hormone resistance in a patient with a novel truncated TR mutant. Journal of Clinical Endocrinology and Metabolism $2001865142-5147$.

8 Behr M, Ramsden DB \& Loos U. Deoxyribonucleic acid binding and transcriptional silencing by a truncated c-erbA $\beta 1$ thyroid hormone receptor identified in a severely retarded patient with resistance to thyroid hormone. Journal of Clinical Endocrinology and Metabolism 199782 1081-1087.

9 Ono S, Schwartz ID, Mueller OT, Root AW, Usala SJ \& Bercu BB. Homozygosity for a dominant negative thyroid hormone receptor gene responsible for generalized resistance to thyroid hormone. Journal of Clinical Endocrinology and Metabolism $1991 \quad 73$ 990-994.

10 Refetoff S The thyroid and its diseases, Section 16 D, Thyroid hormone resistance syndromes. www.thyroidmanager.org 2003.

11 Margotat A, Sarkissian G, Malezet-Desmoulins C, Peyrol N, Vlaeminck Guillem V, Wemeau J-L et al. Identification de huit nouvelles mutations dans le gene c-erb $\beta$ chez des patients atteints de résistance aux hormones thyrö̈diennes. Annales d'endocrinologie $200162220-225$.

12 Beck-Pecooz P \& Chatterjee VKK. The variable clinical phenotype in thyroid hormone resistance syndrome. Thyroid $1994 \mathbf{4}$ 225-232.

13 Kahaly G, Matthews C, Mohr-Kahaly S, Richards CA \& Chatterjee VKK. Cardiac involvement in thyroid hormone resistance. Journal of Clinical Endocrinology and Metabolism 200287 204-212.

14 Brucker-Davis F, Skarulis MC, Grace MB, Benichou J, Hauser P, Wiggs E et al. Genetic and clinical features of 42 kindreds with resistance to thyroid hormone. The National Institutes of Health prospective study. Annals of Internal Medicine $1995 \mathbf{1 2 3}$ 572-583.

15 Miyoshi Y, Nakamura H, Tagami T, Sasaki S, Dorin RI, Tnaiyama $\mathrm{M}$ et al Comparison of the functional properties of three different truncated thyroid hormone receptors identified in subjects with resistance to thyroid hormone. Molecular and Cellular Endocrinology 1998137 169-176.

Received 2 December 2003

Accepted 1 March 2004 